\title{
Diretrizes para a fase de projetos de edificações públicas sob o foco da sustentabilidade ambiental: estudo de caso de uma Instituição Federal de Ensino Superior (IFES) de acordo com o sistema de certificação LEED
}

Guidelines for the public building projects phase under the environmental sustainability focus: case study of a Federal Higher Education Institution (IFES) in accordance with the LEED certification system

Lignes directrices pour la phase des projets de construction publics sous l'objectif de la durabilité environnementale: etude de cas d'une Institution Fédérale de l'Enseignement Supérieur (IFES) en conformité avec le système de certification LEED

Directrices para la fase de diseño de construcción pública desde el enfoque de la sostenibilidad ambiental: estudio de caso de una Institución Federal de Educación Superior (IFES), de conformidad con el sistema de certificación LEED

\author{
Roberto Caldeira da Silva* \\ Ludmila de Souza Freitas**
}

Recebido em 18/02/2016; revisado e aprovado em 12/06/2016; aceito em 12/09/2016

DOI: http:/ / dx.doi.org/10.20435/1984-042X-2016-v.17-n.4(17)

Resumo: O objetivo deste artigo é propor melhorias para a fase de projetos de edificações públicas, sob o enfoque do sistema de certificação LEED. A estratégia adotada para a pesquisa foi o estudo de caso de uma Instituição Federal de Ensino Superior (IFES), localizada na cidade de CuritibaPR. O estudo revelou que a edificação não atende a maioria dos itens das categorias previstas no checklist. No entanto, com as diretrizes recomendadas, refez-se a avaliação, conseguindo obter um escore tal que possibilitaria enquadrar a edificação como certificada.

Palavras-chave: sustentabilidade ambiental; edificações públicas; certificação LEED.

Abstract: The aim of this paper is to propose improvements to the stage of public building projects, under the approach of the LEED certification system. The strategy adopted for the research was the case study of a Federal Institution of Higher Education (IFES), located in Curitiba, PR. The study revealed that the building does not meet most of the items of the categories listed in the checklist. However, with the recommended guidelines, remade to evaluation, obtaining a score such that would make it possible to frame the building as certified.

Key words: environmental sustainability; public buildings; LEED certification.

Résumé: Le but de cet article est de proposer des améliorations au stade des projets des bâtiments publics, du point de vue du système de certification LEED. La stratégie adoptée pour la recherche a été l'étude d'une Institution Fédérale de l'Enseignement Supérieur (IFES), situé à Curitiba, PR. L'étude a révélé que le bâtiment ne répond pas à la plupart des points des catégories énumérées dans la liste de contrôle. Cependant, avec des directrices recommandées, l'évaluation a eté refait et il ya reussi, l'obtention d'un score qui permettrait à ce cadre le bâtiment tel que certifié.

Mots-clés: la durabilité environnementale; bâtiments publics; certification LEED.

Resumen: El propósito de este artículo es proponer mejoras en la etapa de los proyectos de edificios públicos, desde el punto de vista del sistema de certificación LEED. La estrategia adoptada para la investigación fue el estudio de caso de una Institución Federal de Educación Superior (IFES), con sede en Curitiba, PR. El estudio reveló que el edificio no cumple con la mayoría de los puntos de las categorías enumeradas en la lista de verificación. Sin embargo, con las directrices recomendadas, evaluación fue rehecha a la, obteniendo de una puntuación que permitio dejar el edificio conforme la certificación.

Palabras clave: sostenibilidad ambiental; edificios públicos; la certificación LEED.

\footnotetext{
* Universidade Tecnológica Federal do Paraná (UTFPR), Curitiba, Paraná, Brasil.
}

** Universidade Federal do Paraná (UFPR), Curitiba, Paraná, Brasil. 


\section{INTRODUÇÃO}

Nas décadas de 1970 e 80, a preocupação ambiental da sociedade estava focada nos processos de produção, e os regulamentos ambientais concentraram-se na poluição das indústrias. No entanto, no final dos anos 1980 e durante década de 1990, houve um crescente reconhecimento em que, tanto na fase de utilização quanto na fase de descarte, a adoção de práticas mais sustentáveis são importantes no ciclo de vida do produto. Assim, esse cenário exigiu uma nova abordagem para a concepção dos produtos, visando a todas as fases do ciclo de vida. O desenvolvimento sustentável é hoje uma questão-chave para a sociedade em todo o mundo, bem como para os setores de comércios, indústrias e governos. Para a construção civil, isto significa que as instalações devem ser produzidas com um mínimo de impacto ambiental sobre todas as fases do ciclo de vida da edificação, nas quais o foco tem sido principalmente sobre a minimização da energia para a operação e otimização da utilização de materiais de construção (THORMARK, 2001a).

Para Durmisevic e Brouwer (2002), inovações tecnológicas, crescimento populacional, evolução de problemas ecológicos, mudanças na economia e estilo de vida impuseram novos requisitos para o ambiente construído. Esse contexto influencia consideravelmente a maneira como devemos projetar e construir no futuro. No entanto a concepção convencional de projeto ainda se concentra nas propriedades clássicas de construção, função da otimização de custos em relação ao desempenho de curto prazo. Tal abordagem não leva em consideração aspectos relacionados com a futura transformação da edificação e suas consequências ambientais e econômicas.

Esse cenário evidencia que o desenvolvimento econômico da sociedade moderna é baseado em um sistema industrial, que consome uma enorme quantida- de de materiais e energia em uma base de fluxo contínua. Assim, é óbvio que será cada vez mais difícil sustentar a qualidade de vida se esforços sérios não forem realizados para incentivar o uso racional dos recursos limitados do planeta e a redução da produção de resíduos. (DURMISEVIC; VAN IERSEL, 2003).

Berge (2003) menciona que a indústria da construção é, depois da produção de alimentos, a maior consumidora de matérias-primas no mundo de hoje, onde um objetivo amplamente aceito para um futuro sustentável é a redução drástica da utilização de recursos naturais.

Estas e outras preocupações ambientais com a saúde global têm motivado um número crescente de projetistas, construtores e usuários para buscar estratégias ambientalmente mais sustentáveis de projeto e construção. No entanto, em comparação com outros "produtos", edifícios são mais difíceis de serem avaliados, pelos seguintes motivos: são grandes em escala, complexos em materiais e função, e temporalmente dinâmicos, devido à vida útil limitada de componentes de construção e alterações das necessidades dos usuários; seu processo de produção é menos padronizado em função do carácter único para cada edifício; possui informações quantitativas limitadas sobre os impactos ambientais da produção e fabricação de materiais de construção, ou o próprio processo de construção e demolição (SCHEUER et al., 2003).

As obras públicas são planejadas e concebidas para serem executadas e concluídas dentro do prazo estipulado, no valor estimado e em conformidade com a legislação e os parâmetros especificados no Edital de licitação. Além dessas premissas básicas, uma edificação pública deve primar pela sustentabilidade, ou seja, minimizar os impactos gerados ao meio ambiente e aos usuários, bem como ser projetada e construída visando a uma vida útil prolongada a custos de execução e manutenção viáveis (MOTTA, 2005). 
Tendo em vista esse cenário que se apresenta, em 2010 o governo federal do Brasil publicou a Instrução Normativa n. 01/2010 (BRASIL, 2010) - que trata dos critérios de sustentabilidade ambiental para aquisição de bens, contratação de serviços ou obras pela Administração Pública Federal - enfatizando que, na contratação das obras e serviços de engenharia, conforme o Art. $4^{\circ}$ nos termos do art. 12 da Lei n. 8.666 (BRASIL, 1993),

[...] as especificações e demais exigências do projeto básico ou executivo, para contratação de obras e serviços de engenharia, devem ser elaborados visando à economia da manutenção e operacionalização da edificação, à redução do consumo de energia e água, bem como à utilização de tecnologias e materiais que reduzam o impacto ambiental.

Posteriormente foi publicada a Instrução Normativa n. 02/2014 (BRASIL, 2014), a qual dispõe sobre a obrigatoriedade de as edificações públicas obterem a Etiqueta Nacional de Conservação de Energia (ENCE), Geral de Projeto classe " $A$ " e Geral de Edificação Construída classe " $A$ ", onde é avaliada a conformidade da envoltória da edificação e dos sistemas de iluminação e condicionamento de ar.

Cabe ressaltar que os critérios de sustentabilidade para o espaço construído muitas vezes representam um investimento inicial alto, mas que, ao longo da vida útil do empreendimento, vão sendo minimizados por meio dos ganhos com eficiência energética, uso racional da água e durabilidade da edificação.

Assim, os principais esforços para implementação de critérios de sustentabilidade ambiental e inovação em edificações públicas devem estar voltados para concepção dos projetos, especificamente na elaboração do projeto básico, pois, nessa etapa, a possibilidade de intervenção é muito maior, e os custos envolvidos na necessidade de adequações são muito menores que nas demais etapas que compõem o ciclo de vida dessa tipologia de edificação.

Nesse contexto, esta pesquisa pretendeu analisar a sustentabilidade de edificações públicas sob o enfoque do sistema de certificação LEED.

Tendo em vista a pesquisa de Silva (2012) que contemplou o estudo de caso realizado em uma Instituição Federal de Ensino Superior (IFES), de acordo com o sistema de certificação LEED, o objetivo geral do presente trabalho é propor diretrizes para a fase de projetos de edificações públicas, sob o foco da sustentabilidade ambiental.

Os objetivos específicos da pesquisa consistiram em:

- Realizar uma análise comparativa dos principais sistemas de certificação atuantes no Brasil e adotar o mais adequado à realidade da instituição;

- Avaliar, por meio do estudo de caso, o nível de utilização da certificação LEED nas edificações da IFES;

- Indicar os itens deficitários da edificação de estudo, com relação aos parâmetros da certificação adotada;

- Avaliar a possibilidade de adequar a edificação aos critérios da certificação;

- Propor soluções de projeto visando cumprir as exigências mínimas para tornar as futuras edificações da IFES compatíveis com os requisitos da certificação.

\section{JUSTIFICATIVA}

Durmisevic (2006) pondera que:

Para compreender o impacto que a indústria da construção presta em moldar o nosso futuro comum, é necessária uma análise sob uma perspectiva global. A indústria da construção é um setor vital da nossa sociedade e é visto em muitos segmentos da sociedade como um indicador de crescimento econômico e prosperidade. A construção 
civil contribui com uma média de $10 \%$ do PIB, e mais da metade do investimento de capital em todos os países. A indústria da construção estima ter 111 milhões de empregados a nível mundial, e é, portanto, o maior empregador industrial a nível global (CICA, 2002). Cerca de $50 \%$ das terras do planeta foram transformadas por atividades humanas (Estratégia de desenvolvimento sustentável para 2.002), e atualmente mais de $50 \%$ da população vive em cidades, com este percentual crescendo gradativamente $(\mathrm{CIB}$, 1999). Além disso, o impacto da indústria da construção no meio ambiente se estende para além da fase de construção, incluindo as questões da cadeia de fornecimento e os efeitos das atividades pós-construção: operação, manutenção e reúso do edifício (CRISP, 1999). Portanto, a indústria da construção civil está diretamente relacionada com outros grandes setores: mineração, manufatura, agricultura e transporte. Incluindo todas as atividades acima mencionadas, este setor é responsável por $50 \%$ das emissões globais de gases de efeito estufa (UNEP-IETC, 2002) que o torna o maior contribuinte individual para as emissões destes gases a nível mundial (CIB, 1999). Em muitos países, a indústria da construção é responsável por até $40 \%$ dos materiais que entram na economia global (CIWMB, 2000), $50 \%$ da produção de resíduos, e $40 \%$ do consumo de energia (ANINK, 1996).

Nos últimos anos, a perspectiva da vida útil das edificações revelou um aumento crescente do consumo energético, visto que o ciclo de vida de uma edificação compreende as etapas de construção (incluindo todos os processos, desde a extração de matérias-primas até a ma- nufatura dos materiais e equipamentos), montagem, operação, manutenção e demolição (THORMARK, 2001b).

Diante desse cenário, a preocupação com a questão ambiental passou a ser levantada nos mais diversos setores da sociedade, promovendo a gradativa adesão dos diferentes setores mercadológicos. A busca do equilíbrio entre o que é socialmente desejável, economicamente viável e ecologicamente sustentável é usualmente descrita em função da chamada "triple bottom line", que congrega as dimensões ambiental, social e econômica do desenvolvimento sustentável (SILVA, 2003).

Consequentemente, é possível afirmar que o desempenho de uma edificação está intimamente ligado à sua concepção, ou seja, ao modo como foi projetada e construída, tendo em vista os materiais empregados e os sistemas construtivos. Uma edificação sustentável não é apenas aquela que utiliza materiais ambientalmente corretos ou que recicla os resíduos gerados da construção, mas sim a que adota princípios de conforto térmico e de iluminação, visando à eficiência energética e a um ambiente salubre, como também ao aproveitamento da água da chuva e à facilidade de manutenção e desmonte da edificação quando for o momento (BORGES, 2008).

Em síntese, Durmisevic (2006) afirma que tais processos de construção altamente ineficientes afetam os sistemas econômicos, ambientais e sociais, e são resultado de práticas competitivas tradicionais de construção, focadas em três fatores: custos de construção, qualidade e tempo. Contrariamente a esse cenário, o novo paradigma traz uma abordagem sustentável para a construção civil, além dos tradicionais fatores, pois o todo faz parte de um contexto global sustentável, sendo os principais fatores as dimensões ambiental, econômica e sociais, conforme ilustrado na Figura 1: 


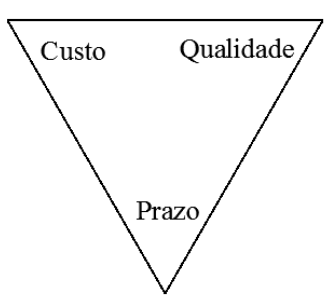

Fatores competitivos de processos de edifícios tradicionais

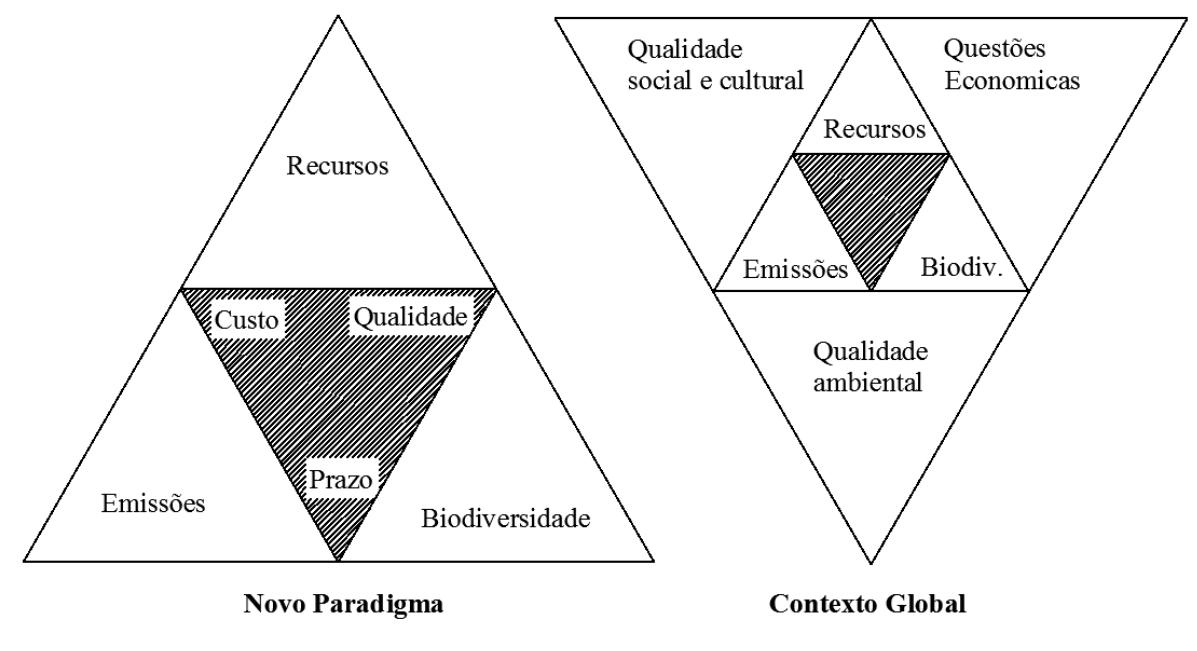

Figura 1 - Progresso da abordagem sustentável na construção civil Fonte: Adaptado de Durmisevic (2006)

Frente a esse novo paradigma e ao contexto global para sustentabilidade na construção civil, nos Estados Unidos o United States Green Building Council (USGBC, 2009) desenvolveu, no ano 1999, um sistema de certificação ambiental divulgado e aplicado internacionalmente, o Leadership in Energy and Environmental Design (LEED). No Brasil, esse modelo está representado pelo GBC Brasil, no entanto o organismo certificador permanece sendo o USGBC nos Estados Unidos. A certificação confirma que os empreendimentos foram projetados e construídos por meio de estratégias destinadas a melhorar o desempenho em termos de energia, água, redução da emissão de $\mathrm{CO}_{2}$, melhor qualidade do ambiente interior, administrando o uso dos recursos naturais e minimizando os impactos ambientais (DEGANI, 2010).

De acordo com Silva (2003) o LEED é provavelmente o método disponível mais amigável enquanto ferramenta de projeto, o que facilita a sua incorporação à prática profissional. Do mesmo modo, o LEEDNC (New Construction) é uma certificação baseada na pontuação de sete grandes áreas: Espaço sustentável; Uso racional da água; Energia e atmosfera; Materiais e recursos; Qualidade ambiental interna; Inovação e processo de projeto e; Créditos regionais. O objetivo do LEED é acelerar a adoção das práticas dos Edifícios Verdes (GBC BRASIL, 2011).

Ressalta-se que o conceito de construção sustentável é variável de acordo com as prioridades de cada país e está relacionado diretamente com as especificidades de seu clima, tradições construtivas, estágio de desenvolvimento industrial, cultura, natureza das edificações existentes e características dos diversos agentes envolvidos (DEGANI, 2010).

Assim, tendo em vista a atual conjuntura da sociedade, em termos de um desenvolvimento sustentável, é de suma importância conceber edificações públicas tendo como objetivos: o emprego consciente de materiais; a facilidade de construção e manutenção; a eficiência energética; conforto ambiental; o uso racional da água; e a economicidade.

No intuito de ilustrar o panorama do processo de certificação LEED no Brasil, de acordo com publicação no site oficial do Green Build Council (GBC) Brasil, destaca-se da Figura 2 que os registros de empreendimentos públicos representam $2,9 \%$, onde esse cenário 
demonstra que a Administração pública, se comparada com a iniciativa privada e os demais segmentos, responde por um pequeno percentual de empreendimentos com critérios de sustentabilidade ambiental.

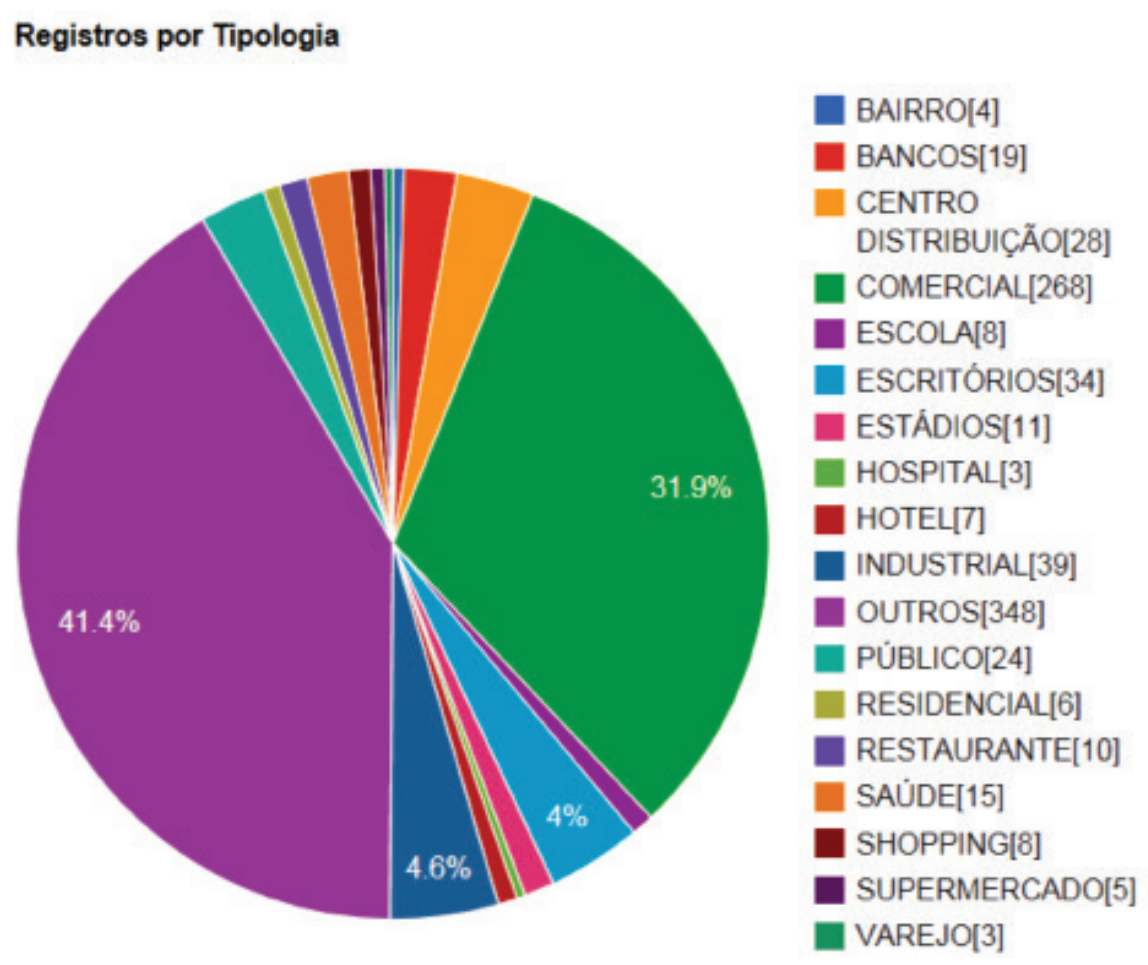

Figura 2 - Percentual de certificação LEED por tipologia do empreendimento

Fonte: GBC Brasil (2013)

Ademais, é possível afirmar que, para investidores e empreendedores privados, a viabilidade de um projeto é condição de sua capacidade de gerar retorno financeiro sobre o capital investido, isto é, de produzir lucro, ou seja, o investimento no projeto deve ser rentável (ROSA, 2005).

Dessa forma, todo empreendimento, depois de idealizado e realizado o projeto básico (composto por estudos, anteprojetos e orçamento estimativo), passa por uma etapa de viabilidade financeira. Essa etapa é primordial e define se o empreendimento terá prosseguimento ou será revisto e adaptado, do que se entende que um empreendimento, para ser viável financeiramente, deve gerar retorno financeiro ao empreendedor ou proprietário.

Nesse sentido, as construções sustentáveis tendem a utilizar materiais e sistemas construtivos que atualmente apresentam preços superiores aos convencionais, mas que, ao longo do tempo, esses custos serão recuperados com o aumento da vida útil da edificação e com a redução dos custos de operação e manutenção. Para tanto, deve-se ter em vista que o custo global de construção depende da vida útil projetada, sendo o custo global a soma dos custos de aquisição mais os custos de operação e uso, considerando o desmonte do bem após o final da vida útil (BORGES, 2008).

Portanto, numa edificação pública sustentável, no caso em questão de uma IFES, o retorno financeiro está na durabilidade e conforto que a edificação proporcionará aos usuários, bem como na economia de recursos para o governo com a adoção de critérios que economizem e 
racionalizem o consumo de recursos, ou seja, a eficiência energética e o uso racional da água.

Quanto aos fatores sociais, as obras de edificações públicas norteiam-se pela excelência e pelo bem social que elas proporcionam à população e não apenas pelo enorme volume de recursos que as envolvem. Estas são concebidas para atender a sociedade em suas necessidades básicas, tais como: hospitais, escolas, universidades, aeroportos e casas populares (SILVA, 2009).

Nesse contexto, de acordo com a tendência que se apresenta de uma construção civil mais sustentável, a presente pesquisa justifica-se tendo em vista que grande parcela do setor é motivada pelos órgãos públicos e que a sociedade é atingida tanto pelas benfeitorias de uma obra pública, como também pelos impactos ambientais decorrentes da escassez dos recursos naturais e dos resíduos gerados.

\section{MÉTODO}

O trabalho abordou a metodologia de avaliação da sustentabilidade ambiental de uma edificação da IFES, de acordo com os parâmetros definidos no sistema de certificação LEED-NC versão 2010. O estudo realizado é qualitativo, e não faz parte do escopo do trabalho a abordagem de métodos quantitativos nem ensaios de materiais.

Da análise comparativa apresentada na pesquisa de Silva (2012), foi possível verificar que a metodologia mais bem estruturada e com maior facilidade de aplicação foi a LEED-NC, pois seu formato em checklist é mais apropriado para etapa de pesquisa de campo, além de ser a mais difundida com relação à divulgação das práticas de edificações sustentáveis.

Nesse sentido, não se pretendeu certificar a edificação estudada, mas, sim, orientar projetistas quantos às decisões de projeto que podem minimizar os impactos ambientais gerados pelo ambiente construído.

As fontes de evidências foram aplicadas na coleta de dados para avaliar o desempenho ambiental da edificação estudada, a qual foi baseada no checklist do sistema de certificação ambiental LEED. De acordo com o desempenho atingido, foi determinada a pontuação do edifício e o nível de certificação.

O desempenho ambiental do edifício foi avaliado de forma global, ao longo de todo o seu ciclo de vida, numa tentativa de considerar os preceitos essenciais do que constituiria um green building.

Nesta pesquisa, primeiramente foi realizada a análise individual dos dados das fontes de evidência, sendo posteriormente utilizada a técnica de triangulação de dados entre os resultados das fontes de evidências.

\subsection{Definição do caso}

O estudo de caso foi uma edificação escolar da Instituição Federal de Ensino Superior (IFES), denominada Bloco B, situada no município de Curitiba-PR, a qual foi recebida para uso em março de 2011 (Figura 3). Essa edificação abriga ambientes com diferentes especificidades, sendo composta por salas de aula, anfiteatros, biblioteca, restaurante universitário e banheiros. A diversidade de uso dos ambientes internos foi o que motivou a escolha dessa edificação para o estudo de caso. 


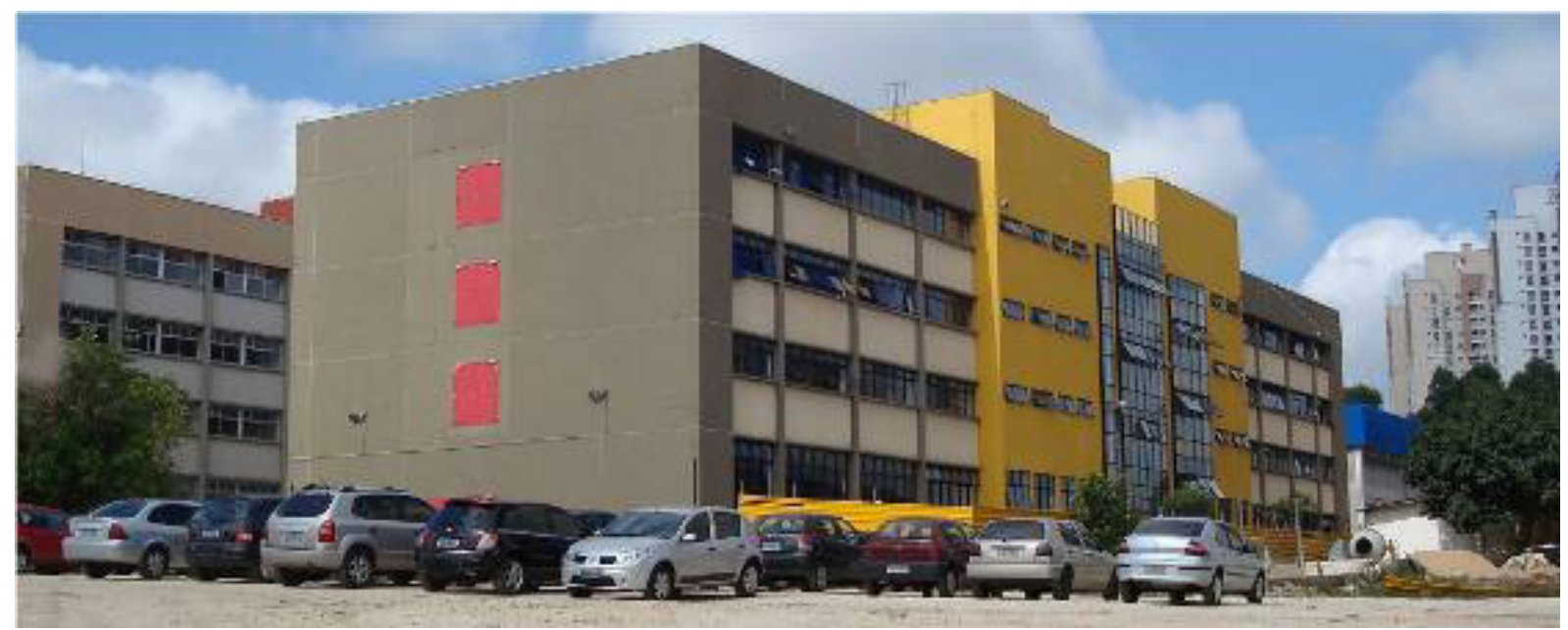

Figura 3 - Fotografia da edificação

Fonte: Silva (2012)

Este bloco foi construído dentro das metas do Programa de Reestruturação e Expansão das Universidades Federais (REUNI), sendo que, na ocasião da concepção dos projetos, os principais parâmetros levados em consideração foram: qualidade, custo e prazo de execução.

A edificação possui área total de $5.556,34 \mathrm{~m}^{2}$, distribuída em quatro pavimentos, concebida da seguinte maneira: Estrutura: pré-fabricada com lajes do tipo alveolares; Vedação: alvenaria de tijolos cerâmicos revestida com argamassa de cimento e cal; Cobertura: estrutura metálica com telhas ecológicas (caixas tetrapak); Esquadrias: ampla área de janelas em alumínio (janelas máximo-ar) e "peles" de vidro nas áreas de corredor central e escadaria; Pavimentação: em piso vinílico anti-derrapante nas salas e corredores, carpet nos anfiteatros, cerâmico nos sanitários e cozinha, e piso podotátil nas áreas de circulação; Hidráulica: torneira dos banheiros tipo acionamento automático; cisterna para captação de águas pluviais; sistema de prevenção de incêndio composta por rede de hidrantes; nas instalações sanitárias não estão previstos o aproveitamento da água de chuva para os vasos sanitários nem há previsão de utilização de água de reúso do efluente das torneiras dos banheiros; Elétrica: instalação elétrica composta por luminárias fluorescentes; rede lógica e de telecomunicações; Divisórias: gesso acartonado (drywall) para as salas de aula, possibilitando flexibilidade de layout, e granito nos banheiros; Serralheria: duas escadas laterais de emergência e corrimão com guarda-corpo nas escadas.

A Figura 4 apresenta o plano diretor completo do campus da IFES, o qual é composto por dois terrenos, um de frente para o outro, sendo que futuramente está prevista a integração de ambos por meio de uma passarela sobre a via expressa de trânsito de ônibus. 


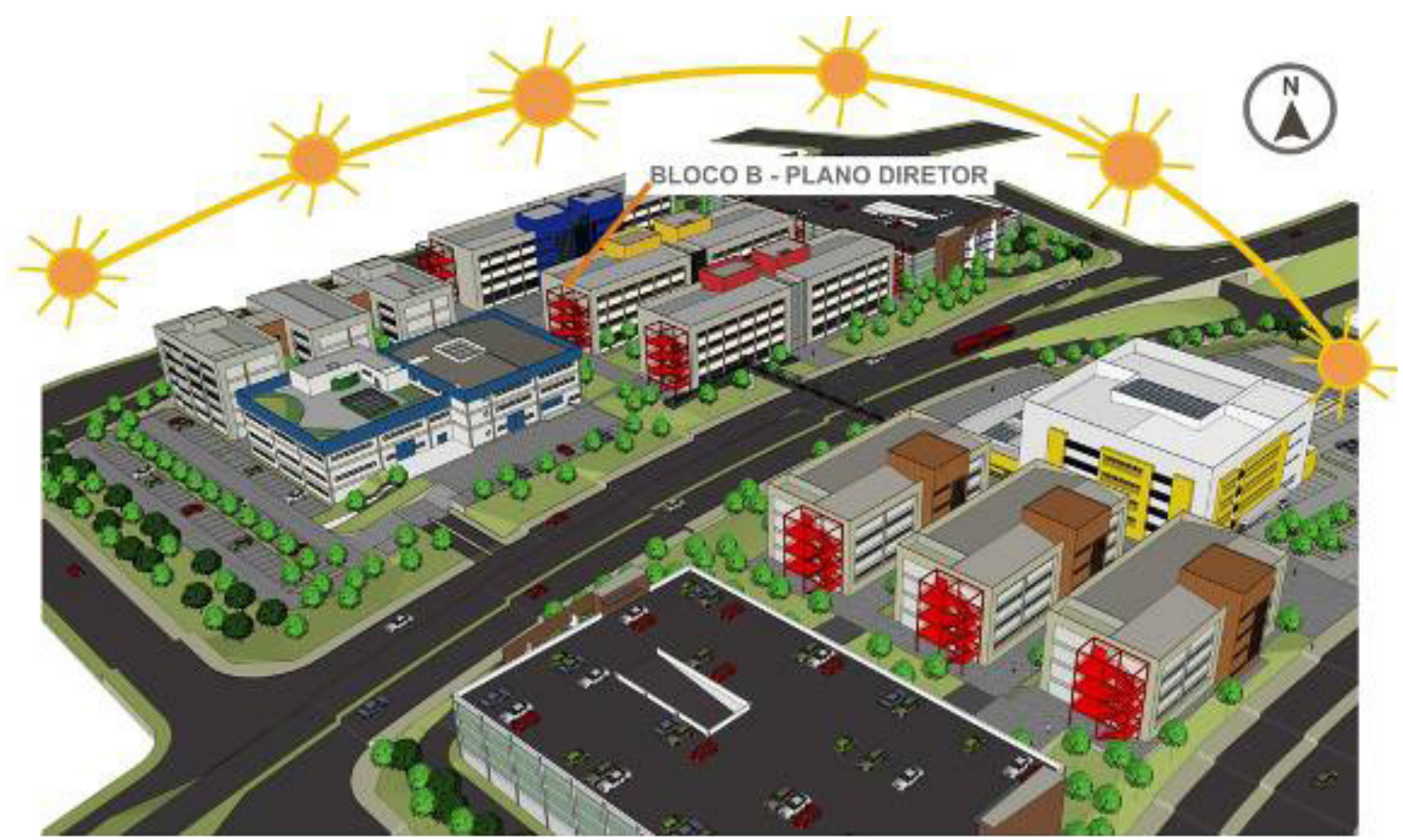

Figura 4 - Implantação da edificação no campus Ecoville com todo plano diretor realizado Fonte: Silva (2012)

\subsection{Avaliação}

O procedimento para avaliação consistiu no estudo de campo da edificação in loco, ou seja, procedendo a análise de acordo com a edificação executada e em uso, confrontando-a com os créditos da certificação. As fontes de evidência para tanto foram: observação-participante, documentos relacionados à edificação (projetos, memoriais, planilhas, etc.) e aplicação de questionários com engenheiros e arquitetos que atuam na concepção e fiscalização de obras públicas.

A avaliação foi realizada de acordo com as categorias constantes da metodologia de certificação ambiental LEED-NC. Cada categoria apresenta um checklist com uma série de créditos, totalizando 110 pontos, os quais foram relacionados à edificação em estudo e cuja soma nas categorias identifica o nível de certificação atingido, sendo: Certificado 40 a 49 pontos; Prata 50 a 59 pontos; Ouro 60 a 79 pontos; e Platinum 80 pontos ou mais. O Quadro 1 contém a representação em percentual de cada categoria pontuada pelo LEED-NC.

\begin{tabular}{|c|c|}
\hline \multicolumn{2}{|c|}{ REPRESENTAÇÃO PERCENTUAL DE CADA CATEGORIA } \\
\hline \multirow{2}{|c|}{ CATEGORIA } & $\%$ \\
\hline \multirow{2}{*}{ USPAÇO SUSTENTÁVEL } & $24 \%$ \\
\hline ENACIONAL DA ÁGUA & $9 \%$ \\
\hline M MATERIAIS E RECURSOS & $32 \%$ \\
\hline Q QUALIDADE AMBIENTAL INTERNA & $14 \%$ \\
\hline INOVAÇÃO E PROCESSO DE PROJETO & $5 \%$ \\
\hline CRÉDITOS REGIONAIS & $4 \%$ \\
\hline
\end{tabular}

Quadro 1 - Representação percentual de cada categoria do LEED-NC em relação à pontuação total

Fonte: Silva (2012)

Conforme a análise realizada de acordo com a edificação executada e em uso, confrontando-a com os créditos da certificação mencionados anteriormente, a seguir são apresentados os resultados da avaliação realizada. 
O Quadro 2 apresenta, de maneira resumida, os resultados do checklist em cada categoria analisada de acordo com a certificação LEED-NC. Dessa forma, tendo em vista os 19 pontos atingidos na verificação global da edificação, é possível afirmar que o nível de sustentabilidade ambiental da edificação está muito abaixo do mínimo que seria de 40 pontos.

\begin{tabular}{|cc|c|c|}
\hline \multicolumn{4}{|c|}{ RESUMO DO RESULTADO DA ANÁLISE DO ESTUDO DE CASO } \\
\hline & CATEGORIA & 26 & 14 \\
\hline 0 & ESPAÇO SUSTENTÁVEL & 10 & 0 \\
\hline 0 & USO RACIONAL DA ÁGUA & 35 & 0 \\
\hline & ENERGIA ATMOSFERICA & 14 & 1 \\
\hline & MATERIAIS E RECURSOS & 15 & 3 \\
\hline & QUULIDADE AMBIENTAL INTERNA & 6 & 0 \\
\hline & INOVAÇÃO E PROCESSO DE PROJETO & 4 & 1 \\
\hline & CRÉDITOS REGIONAIS & $\mathbf{1 1 0}$ & $\mathbf{1 9}$ \\
\hline
\end{tabular}

Quadro 2 - Resumo do resultado da avaliação do LEED-NC Fonte: Silva (2012)

\section{DISCUSSÃO E RECOMENDAÇÕES}

A análise da edificação do estudo de caso, de acordo com a metodologia de certificação ambiental adotada, permitiu propor algumas recomendações de projeto, no intuito de melhorar a pontuação atingida nas categorias do checklist, para que as futuras edificações públicas possam ser concebidas de forma mais sustentáveis, priorizando a durabilidade, o conforto ambiental, a eficiência energética e o uso racional da água.

É importante ressaltar que, para cada recomendação proposta, deve ser considerado o tempo de retorno do investimento e o ganho ambiental resultante. Há casos em que o retorno financeiro é rápido, e outros, em longo prazo, ou seja, é necessário ponderar o ganho ambiental e o retorno financeiro, pois de nada adianta uma solução ambientalmente correta, mas que tenha altos custos de implantação e manutenção, ou seja, para a solução ser sustentável tem que levar em consideração o meio ambiente, as pessoas envolvidas e os custos financeiros de implantação e operação, principalmente por tratar-se de uma edificação pública.

O Quadro 3 apresenta a síntese das diretrizes de projeto e recomendações para a construção de edificações públicas mais sustentáveis, considerando os parâmetros constantes da metodologia de certificação ambiental LEED-NC. 
ambiental: estudo de caso de uma Instituição Federal de Ensino Superior (IFES) de acordo com o sistema de certificação LEED

\begin{tabular}{|c|c|c|}
\hline \multicolumn{2}{|r|}{ Item } & Recomendação \\
\hline & $\begin{array}{c}\text { ESPAÇO } \\
\text { SUSTENTÁVEL }\end{array}$ & $\begin{array}{l}\text { - Na ocasião da análise da viabilidade do terreno, priorizar áreas onde } \\
\text { haja facilidade de acesso ao transporte público. } \\
\text { - Atuar na redução do impacto direto ao meio ambiente do local da obra, } \\
\text { atendendo ao disposto na Resolução CONAMA no } 307 / 2002 \text {. } \\
\text { - Canteiro de obras: layout e operação em conformidade com a Norma } \\
\text { Regulamentadora n } 18 \text { do Ministério do Trabalho; redução de perdas por } \\
\text { operação inadequada; uso racional da água (água de chuva) e eficiência } \\
\text { energética (placa solar); adoção de materiais de origem local e com baixa } \\
\text { emissão de CO2; e tratamento e destinação final dos resíduos gerados. } \\
\text { - Destinar áreas no terreno para estacionamento de veículos, bem como } \\
\text { bicicletários e vestiários. }\end{array}$ \\
\hline & $\begin{array}{c}\text { USO RACIONAL } \\
\text { DA ÁGUA }\end{array}$ & $\begin{array}{l}\text { - Aproveitamento da água de chuva. } \\
\text { * priorizar a água de chuva para descarga de vasos sanitários e rega de } \\
\text { jardim } \\
\text { - Reuso da água. } \\
\text { * priorizar a água de reuso para lavagem de calçadas } \\
\text { - Aparelhos economizadores de água. }\end{array}$ \\
\hline & $\begin{array}{l}\text { ENERGIA E } \\
\text { ATMOSFERA }\end{array}$ & $\begin{array}{l}\text { - Comissionamento dos sistemas elétricos. } \\
\text { - Adoção de luminárias com lapadas de LED; } \\
\text { - Para áreas de circulação, corredores e escadas adotar luminárias com } \\
\text { dispositivo sensor de presença. } \\
\text { - Sempre que possível, utilizar fontes alternativas de geração de energia } \\
\text { (solar) } \\
\text { - Adotar aparelhos elétrico/eletrônicos com selo PROCEL de eficiência } \\
\text { energética nível A. }\end{array}$ \\
\hline (18) & $\begin{array}{l}\text { MATERIAIS E } \\
\text { RECURSOS }\end{array}$ & $\begin{array}{l}\text { - Atender ao disposto na Instrução Normativa } N^{\circ} 01 \text {, de } 19 \text { de janeiro de } \\
2010 . \\
\text { - Adotar materiais com baixa emissão de } \mathrm{CO}^{2} \text {. } \\
\text { - Adotar materiais de origem regional. } \\
\text { - Especificar materiais levando em consideração aspectos ambientais e } \\
\text { sociais além do preço e qualidade. } \\
\text { - Sempre que possível utilizar materiais provenientes de reuso e/ou de } \\
\text { conteúdo reciclado. }\end{array}$ \\
\hline & $\begin{array}{l}\text { QUALIDADE } \\
\text { AMBIENTAL } \\
\text { INTERNA }\end{array}$ & $\begin{array}{l}\text { - Adotar materiais livres de compostos orgânicos voláteis (VOC) (tintas, } \\
\text { vernizes, madeiras compostas). } \\
\text { - Conceber projetos priorizando a ventilação cruzada e insolação } \\
\text { - Adotar brises para controle da incidência solar } \\
\text { - Manter o ambiente interno livre da fumaça do cigarro. }\end{array}$ \\
\hline & $\begin{array}{l}\text { INOVAÇÃO E } \\
\text { PROCESSO DE } \\
\text { PROJETO }\end{array}$ & $\begin{array}{l}\text { - Conceber projetos de edificações sustentáveis visando reduzir os custos } \\
\text { de operação e manutenção }\end{array}$ \\
\hline (0) & $\begin{array}{l}\text { CRÉDITOS } \\
\text { REGIONAIS }\end{array}$ & $\begin{array}{l}\text { - Levar em consideração as prioridades ambientais específicas da região, } \\
\text { de acordo com legislação dos órgãos competentes }\end{array}$ \\
\hline
\end{tabular}

Quadro 3 - Recomendações para edificações mais sustentáveis

Fonte: Silva (2012)

Tendo em vista as diretrizes sugeridas, verificou-se que a edificação do estudo de caso teria condições de obter a certificação LEED-NC. Para tanto, foi elaborado o Quadro 4 o qual apresenta a pontuação que seria alcançada na verificação in loco da edificação, caso fossem implementadas as recomendações de melhorias. 


\begin{tabular}{|cc|c|c|}
\hline \multicolumn{3}{|c|}{ RESUMO DA AVALIAÇÃO APÓS AS IMPLEMENTACOES RECOMENDADAS } \\
\hline CATEGORIA & 26 & 17 \\
\hline & ESPAÇO SUSTENTÁVEL & 10 & 4 \\
\hline 0 & USO RACIONAL DA ÁGUA & 35 & 6 \\
\hline & ENERGIA ATMOSFERICA & 14 & 6 \\
\hline & MATERIAIS E RECURSOS & 15 & 10 \\
\hline & QUALIDADE AMBIENTAL INTERNA & 6 & 1 \\
\hline 0 & INOVAÇÃO E PROCESSO DE PROJETO & 4 & 1 \\
\hline & CRÉDITOS REGIONAIS & $\mathbf{1 1 0}$ & $\mathbf{4 5}$ \\
\hline
\end{tabular}

Quadro 4 - Resumo da pontuação considerando as diretrizes recomendadas

Fonte: Silva (2012)

Assim, a edificação poderia ser enquadrada como CERTIFICADA, pois totalizou 45 pontos, ficando dentro da margem estipulada para a categoria que é de 40 a 49 pontos.

Por analogia, pode-se verificar que as IFES, assim como as demais edificações públicas, têm condições de conceber projetos para tornar suas edificações mais sustentáveis, bem como há a possibilidade de obter uma certificação LEED para essa tipologia de edificações.

\section{CONSIDERAÇÕES FINAIS}

Este trabalho propôs demonstrar a avaliação da sustentabilidade ambiental das edificações da IFES, tendo em vista o sistema de certificação LEED, no qual se verificou que é possível aplicar a metodologia demonstrada em outras tipologias de edificações.

A pesquisa contemplou a verificação minuciosa na edificação do estudo de caso, tendo como fontes de evidências os projetos, caderno de encargos, questionário aplicado à equipe de projetos e vistoria in loco. O objetivo foi verificar o nível de enquadramento da edificação, como construída, com relação aos itens da certificação LEED-NC.

Ressalta-se que o objetivo principal não foi a certificação, mas, sim, identificar se as obras de edificações públicas brasileiras podem incorporar ações de projeto que minimizem os impactos ambientais.

Assim, com a verificação in loco, foi possível concluir que a edificação não atende a maioria dos itens das categorias previstas no checklist, alcançado uma pontuação muito baixa, insuficiente para obter uma certificação, caso esse fosse o objetivo. No entanto, considerando a proposta de diretrizes de projeto e recomendações, refez-se a avaliação, conseguindo obter um escore de 45 pontos, o qual possibilitaria enquadrar a edificação como certificada, conforme a escala de 40 a 49 pontos.

Consequentemente, é possível afirmar que a administração pública possui condições de conceber edificações mais sustentáveis, levando em consideração, na elaboração dos projetos e no controle e fiscalização das obras, as questões relativas ao uso racional da água e dos materiais, a preservação dos recursos naturais, a valorização da mão de obra local, a eficiência energética e o conforto do usuário, tendo em vista todas as etapas do ciclo de vida da edificação.

Para tanto, é preciso atentar que a principal intervenção deve partir dos profissionais envolvidos na elaboração dos projetos, pois é preciso desenvolver 
e incentivar a concepção projetual sob o ponto de vista do novo paradigma, o qual agrega, além dos já tradicionais preço, prazo e qualidade, também as dimensões social e ambiental da sustentabilidade.

Ressalta-se que tais implementações devem ser motivadas pelos responsáveis pela gestão dos recursos públicos, pois frequentemente há certa resistência a mudanças e uma tendência a se manter os métodos tradicionais de pensar e agir, sendo a inovação muitas vezes uma meta que deve ser atingida gradativamente.

Em síntese, espera-se que as diretrizes de projeto propostas no presente estudo contribuam para o conhecimento científico do tema em questão e orientação a engenheiros e arquitetos na tomada de decisão para o processo de inovação na concepção de projetos, fornecendo elementos importantes para implantação de um padrão de procedimento sustentável que possibilite incentivar o setor de pesquisa e desenvolvimento de materiais e produtos, na busca de soluções que apresentem custo benefício satisfatório, durabilidade, responsabilidade social e respeito ao meio ambiente.

\section{REFERÊNCIAS}

BERGE, B. The ecology of building materials. Oxford: Architectural Press, 2003.

BORGES, Carlos A. de M. O conceito de desempenho das edificações e a sua importância para o setor da construção civil. 2006. Dissertação (Mestrado em Engenharia) - Escola Politécnica da Universidade de São Paulo, São Paulo, 2008.

BRASIL. Instrução Normativa n. 01, de 19 de janeiro de 2010. Dispõe sobre os critérios de sustentabilidade ambiental na aquisição de bens, contratação de serviços ou obras pela Administração Pública Federal direta, autárquica e fundacional e dá outras providências. Brasília: SLTI/MPOG, 2010.

Instrução Normativa n. 02, de 04 de junho de 2014. Dispõe sobre regras para a aquisição ou locação de máquinas e aparelhos consumidores de energia pela
Administração Pública Federal direta, autárquica e fundacional, e uso da Etiqueta Nacional de Conservação de Energia (ENCE) nos projetos e respectivas edificações públicas federais novas ou que recebam retrofit. Brasília: SLTI/MPOG, 2014.

Lei n. 8.666, de 21 de junho de 1993. Regulamenta o art. 37 , inciso XXI, da Constituição Federal, institui normas para licitações e contratos da Administração Pública e dá outras providências.

DEGANI, C. M. Modelo de gerenciamento da sustentabilidade de facilidades construídas. 2010. Tese (Doutorado em Engenharia Civil) - Escola Politécnica de Universidade de São Paulo, São Paulo, SP, 2010.

DURMISEVIC, E.; BROUWER, J. Design aspects of decomposable building structures. Delft University of Technology. Department of Building Technology. Proceedings of the CIB Task Group 39 - Deconstruction Meeting, CIB Publication 272. Karlsruhe, Germany, 2002.

DURMISEVIC, E.; VAN IERSEL, T. M. Life cycle coordination of materials and their functions at connectios design for total servisse life of buildings and its materials. Delft University of Technology, Department of Building Technology, The Netherlands. Deconstruction and Materials Reuse. CIB Publication 287. Gainesville, USA, 2003.

DURMISEVIC, E. Transformable building structures: design for disassembly as a way to introduce sustainable engineering to building design \& construction. Doctoral Thesis. Technische Universiteit Delft. Delft, 2006.

GBC BRASIL. Empreendimentos certificados. Green Building Council Brasil, 2013. Disponível em: <www.gbcbrasil.org.br>. Acesso em: 13 mar. 2014.

GBC BRASIL. Checklist da certificação LEEDNC. Green Building Council Brasil. 2011. Disponível em: <www.gbcbrasil.org.br>. Acesso em: 13 mar. 2014.

MOTTA, C. A.P. Qualidade das obras públicas em função da interpretação e prática dos fundamentos da lei 8.666/93 e da legislação correlata. Santa Maria, RS: Tribunal de Contas do Estado do Rio Grande do Sul, 2005. 
ROSA, M. P. Viabilidade econômico-financeira e benefícios ambientais da implantação de uma usina de reciclagem de resíduos da construção civil produzidos em Florianópolis-SC. 2005. Dissertação (Mestrado em Engenharia Civil) - Universidade Federal de Santa Catarina, Florianópolis, 2005.

SCHEUER, C. et al. Life cycle energy and environmental performance of a new university building: modeling challenges and design implications. School of Natural Resources and Environment. University of Michigan, 2003.

SILVA, R. C. Proposta de melhorias para a fase de projetos de edificações públicas sob o foco da sustentabilidade ambiental: estudo de caso de um edifício de uma Instituição Federal de Ensino Superior (IFES) de acordo com o sistema de certificação LEED. 2012. Dissertação (Mestrado em Engenharia de Construção Civil) - PPGCC/Universidade Federal do Paraná, Curitiba, PR, 2012.

. Critérios para licitação e fiscalização em obras de edificações públicas. 2009. Monografia
(Especialização em Gerenciamento de Obras) - Universidade Tecnológica Federal do Paraná, Curitiba, 2009.

SILVA, V. G. Avaliação da sustentabilidade de edifícios de escritórios brasileiros: diretrizes e base metodológica. 2003. Tese (Doutorado em Engenharia Civil) - Escola Politécnica da Universidade de São Paulo, São Paulo, 2003.

THORMARK, Catarina. Recycling potential and design for disassembly in buildings. 2001. Doctoral Thesis. Lund Institute of Technology, Lund University, Lund, Suécia, 2001a.

THORMARK, Catarina. Alow energy building in a life cycle - its embodied energy, energy need for operation and recycling potential. Institute of Technology, Lund University. Lund, Suécia, 2001b.

United Stated Green Building Council (USGBC). LEED 2009 for new construction and major renovations., 2009. Disponível em: <www.usgbc.org>. Acesso em: 10 jun. 2011.

\section{Sobre os autores:}

Roberto Caldeira da Silva: Engenheiro Civil (UFPR), Especialista em Gerenciamento de obras (UTFPR), Mestre em Engenharia de Construção Civil (UFPR), Doutorando em Engenharia Civil (UTFPR), lotado na Diretoria de Projetos e Obras da Universidade Tecnológica Federal do Paraná (UTFPR). E-mail: rcaldeira@utfpr.edu.br

Ludmila de Souza Freitas: Arquiteta e Urbanista (UFMS), Especialista em Design de Interiores (Uniderp), Mestranda em Design (UFPR), lotada no Departamento de Projetos Civis da UTFPR. E-mail: lud.s.freitas@gmail.com 